\title{
Electrochemical Characterization of Rapid Discharge Sintering (RDS) NiO Cathodes for Dye-Sensitized Solar Cells of $p$-Type
}

\author{
Vittoria Novelli', Muhammad Awais ${ }^{2,3}$, Denis P. Dowling,3, Danilo Dini ${ }^{1,3^{*}}$ \\ ${ }^{1}$ Department of Chemistry, University of Rome "La Sapienza", Rome, Italy \\ 2Department of Industrial Engineering, "King Abdulaziz" University, Rabigh, KSA \\ ${ }^{3}$ Solar Energy Conversion Strategic Research Cluster, University College Dublin (UCD), Dublin, Ireland \\ ${ }^{4}$ School of Mechanical and Materials Engineering, University College Dublin (UCD), Dublin, Ireland \\ Email: ${ }^{*}$ danilo.dini@uniroma1.it
}

Received 27 December 2014; accepted 16 January 2015; published 21 January 2015

Copyright (C) 2015 by authors and Scientific Research Publishing Inc.

This work is licensed under the Creative Commons Attribution International License (CC BY).

http://creativecommons.org/licenses/by/4.0/

(c) (i) Open Access

\begin{abstract}
Nickel oxide (NiO) thin films with thickness ranging in the interval $0.2-3.5 \mu \mathrm{m}$ have been deposited onto conductive transparent substrate via the method of plasma-assisted rapid discharge sintering (RDS) with microwave heating starting from $\mathrm{NiO}$ nanoparticles with diameter $50 \mathrm{~nm}$. The optical and electrochemical properties of the RDS NiO films in the pristine state were characterized in non aqueous electrolyte with the solvent 3-methoxy-propionitrile (3-MPN). Upon electrochemical cycling of $\mathrm{NiO}$ in 3-MPN we observed two characteristic oxidation peaks referring to the two nickel centred processes $\mathrm{Ni}(\mathrm{II}) \rightarrow \mathrm{Ni}(\mathrm{III})$ and $\mathrm{Ni}(\mathrm{III}) \rightarrow \mathrm{Ni}(\mathrm{IV})$, which are both localized prevalently on the surface of the metallic oxide. The oxide films prepared with the RDS method were also sensitized with different types of commercial dyes, either organometallic (N719, black dye) or organic (squaraine 2, erythrosine B), to compare the corresponding $p$-type dye-sensitized solar cells ( $p$-DSCs). All dyes here employed matched the energies of their frontier orbitals with the upper edge of NiO valence band and the redox level of the triiodide/iodide couple. The comparison of the performances of the $p$-DSCs based on RDS NiO which differed exclusively for the nature of the sensitizer showed that the extent of electronic conjugation in the structure of the dye is crucial for the control of the photovoltaic performance of the corresponding $p$-DSC.
\end{abstract}

\section{Keywords}

Nickel Oxide, Dye-Sensitized Solar Cell, Solar Energy Conversion, $p$-Type

\footnotetext{
${ }^{*}$ Corresponding author.
}

How to cite this paper: Novelli, V., Awais, M., Dowling, D.P. and Dini, D. (2015) Electrochemical Characterization of Rapid Discharge Sintering (RDS) NiO Cathodes for Dye-Sensitized Solar Cells of $p$-Type. American Journal of Analytical Chemistry, 6, 176-187. http://dx.doi.org/10.4236/ajac.2015.62016 


\section{Introduction}

Nickel oxide ( $\mathrm{NiO})$ is a chemically stable material with semiconducting properties of $p$-type, [1] which is used as electroactive component in several important technologies ranging from batteries [2] to electrochromic windows, [3] [4] and, more recently, from water splitting electrolysers [5] [6] to dye-sensitized solar cells (DSCs) [7] [8] among others [9]. Such a wide applicability of NiO relies on the possibility of modulating its electrical conductivity and optical transmission (when in the configuration of transparent thin films with thickness $l<3 \mu \mathrm{m}$ ) in a controlled fashion by means of electrical fields, chemical/electrochemical doping [3] [4] or irradiation in the UV-visible spectrum [10]. In particular, the utilization of $\mathrm{NiO}$ as alternative cathodic material in DSCs (also known as Grätzel cells) [11] has encouraged since the early years of 2000 [12] the development of preparation procedures [7] [13] [14] and deposition methods [15] for the realization of mesoporous and conductive $p$-type $\mathrm{NiO}$ electrodes in conjunction with the design and the synthesis of appropriate sensitizers [16] [17] that would impart efficient and fast photoinjection of holes from the valence band (VB) of the oxide to the excited dye. This combination of functional materials in a DSC leads to the desired effect of the photoactivated reduction of the oxidized form of the redox shuttle provided that at the anode occurs the reverse process at a comparable rate [12]. Historically DSCs employed the anode (made of $n$-type $\mathrm{TiO}_{2}$ [11] or, less commonly, $\mathrm{ZnO}$ [18]) as the sole photoactive component of the solar cell. In this conventional configuration the cathode of the DSC is constituted by a transparent metallic conductor like fluorine-doped tin oxide (FTO) or indium-doped tin oxide (ITO), covered with metallic nanoparticles that act exclusively as electrocatalytic centres for the reduction of the oxidized form of the redox shuttle while preserving the optical transparency of the substrate [19]. In this context some authors suggested that the replacement of such photoelectrochemically inert cathodes with a $p$-type metal oxide rendered photoactive by dye-sensitization would have improved the performances of DSCs by enhancing the light conversion efficiency [12]. Such an approach led to the definition and the design of tandem DSCs with both electrodes photoactive in the visible-NIR spectrum utilizing a combination of opportune dyes with complementary optical absorption [12]. Tandem DSCs generally ameloriate their photovoltage characteristics compared to the conventional DSCs with a single photoactive component, while lose in current density due to the still lacking matching of the current flows in the best performing sensitized anodes and sensitized cathodes. The latter electrodes defect generally of relatively poor charge injection efficiency [17], high but non utilizable optical self-absorption in the non-sensitized state [20], and trapping of the photoinjected charge caused by the frequent occurrence of redox reactions within $p$-type oxides which are characterized by mixed valence [21]. These drawbacks call for improvements in many directions of research related with $\mathrm{NiO}$ structure and morphology, its sensitization, and the resulting photoelectrochemical properties. In the present work we consider the characterization of the optical and photoelectrochemical properties of the $\mathrm{NiO}$ films obtained via the method of rapid discharge sintering (RDS) in plasma atmosphere [20] when RDS NiO is in the pristine state and operates in nonaqueous electrolyte. The choice of plasma assisted sintering of $\mathrm{NiO}$ nanoparticles as method of sample preparation was motivated by the earlier recognition that this method leads to the production of thin films with high porosity and mechanical stability as required to the electrodes for DSCs [15]. These features achieved through the RDS method allow the penetration of the electrolyte throughout the whole layer of the oxide for a higher efficiency of charge photoinjection, and warrant charge transport throughout the whole oxide layer due to the electrical connectivity between adjacent $\mathrm{NiO}$ nanoparticles and between the NiO coating and the conductive substrate generated by this modality of sintering. Further to that we have also considered the comparative characterization of the $p$-DSCs derived from the sensitization of RDS NiO with the series of commercial dyes N719, black dye (BD), squaraine 2 (SQ2), and erythrosine B (ERY B) (Figure 1) utilizing the same type of NiO cathode.

\section{Experimental Section}

For the deposition of $\mathrm{NiO} 50 \mathrm{~nm}$ nanoparticles of the metal oxide (99.8\% grade from Sigma-Aldrich) were suspended in 2-propanol at a concentration of $20 \mathrm{~g} \cdot \mathrm{L}^{-1}$ to give a slurry for the step of spray deposition. Prior to $\mathrm{NiO}$ deposition the glass substrates $\left(2 \times 2 \mathrm{~cm}^{2}\right)$ were ultrasonically cleaned for $5 \mathrm{~min}$ in methanol followed by acetone. The $\mathrm{NiO}$ particulate layer was spray-deposited onto fluorine doped tin oxide (FTO) coated glass $\left(12 \Omega \cdot \mathrm{sq}^{-1}\right.$, $3 \mathrm{~mm}$ thick) supplied by Solaronix, using the technique reported in Ref. [22] The FTO-covered glass substrate was kept at room temperature during the spraying of $\mathrm{NiO}$ nanoparticles [23]. The area of the $\mathrm{NiO}$ samples was $5 \times$ $5 \mathrm{~mm}^{2}$. The microwave plasma sintering process known as rapid discharge sintering (RDS), was carried out 


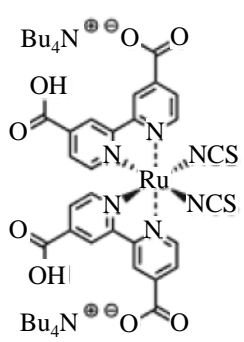

N719

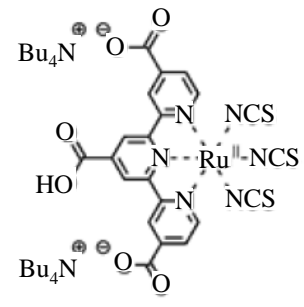

Black Dye

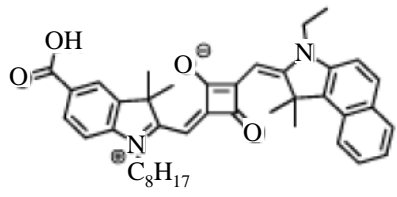

Squaraine 2

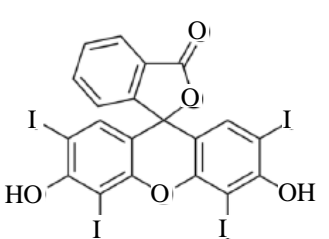

Erythrosine B

Figure 1. Chemical structure of the four dyes utilized for sensitizing the samples of $\mathrm{NiO}$ obtained via microwave sintering in plasma atmosphere.

using a circumferential antenna plasma (CAP) microwave system according to a procedure described in detail in Ref. [24]. Plasmas were formed at a pressure of 5 mbar in an $\mathrm{Ar}$ and $\mathrm{O}_{2}$ (volume ratio: 10/1) atmosphere. For the formation of plasma input powers of $2.4 \mathrm{~kW}$ were used. The input power was generated by a Mugge microwave power supply operating at a frequency of $2.45 \mathrm{GHz}$. Substrate temperatures were measured in-situ during the thermal processing of the substrate using a LASCON QP003 two-colour pyrometer from Dr. Merganthaler GmbH \& Co. For plasma-assisted microwave sintering three $\mathrm{NiO}$ samples were treated simultaneously at a temperature of $\sim 450^{\circ} \mathrm{C}$ with a treatment time of 5 min [15]. Thickness values for the sintered $\mathrm{NiO}$ films are given within a broad range of $1 \mu \mathrm{m}$ (vide infra). This is because the thicker samples obtained with multiple passes of spraying displayed generally a nonuniform thickness [23].

The electrochemical properties of bare $\mathrm{NiO}$ thin films $(0.2 \leq l \leq 3.5 \mu \mathrm{m})$ were studied using a custom-made cell with a three-electrode configuration: NiO-covered FTO was the working electrode, a Pt wire was the counter electrode, and $\mathrm{Ag} / \mathrm{AgCl}$ was used as reference electrode. The electrolytes were $0.2 \mathrm{M} \mathrm{LiClO}_{4}$ in 3-methoxy-proprionitrile (3-MPN), and $0.2 \mathrm{M} \mathrm{KCl,} 0.01 \mathrm{M} \mathrm{KH}_{2} \mathrm{PO}_{4}, 0.01 \mathrm{M} \mathrm{Na}_{2} \mathrm{HPO}_{4}$ in $\mathrm{H}_{2} \mathrm{O}$. All chemicals were purchased from Sigma-Aldrich and were used as received. The applied potential values here reported are all referred to the $\mathrm{Ag} / \mathrm{AgCl}$ electrode $(\mathrm{E}$ vs $\mathrm{NHE}=0.21 \mathrm{~V}$ ). Cyclic voltammetries and chronoamperometric curves were recorded with the potentiostat/galvanostat Autolab PGSTAT 128N, and analyzed with the software NOVA 1.9 .

The sensitisation of plasma sintered $\mathrm{NiO}$ was carried out by immersing $\mathrm{NiO}$ in the ethanol solution of N719 (0.1 mM), BD $(0.1 \mathrm{mM})$, and ERY B $(0.3 \mathrm{mM})$ for $24 \mathrm{~h}$ in the dark and keeping the solution temperature at $60^{\circ} \mathrm{C}$. In the case of $\mathrm{NiO}$ sensitization with SQ2 the dipping time of the electrode in the tincture solution $(0.1$ $\mathrm{mM}$ in ethanol) was $7 \mathrm{~h}$. Dark conditions and the temperature of $60^{\circ} \mathrm{C}$ were maintained also for NiO sensitization with SQ2.

Optical spectra were taken with a spectrophotometer Cary 50, from Varian-Agilent Technologies.

The procedure for the mounting and assembly of the NiO-based dye-sensitized solar cells (DSCs) has been reported in Ref. [25]. For the determination of the characteristic JV curves for the four different $p$-DSCs the intensity of the incident light $\left(I_{i n}\right)$ from the sun simulator was $8.35 \mathrm{~W} \cdot \mathrm{m}^{-2}$.

\section{Results and Discussion}

\subsection{Electrochemical Properties of RDS NiO}

The cyclic voltammogram of microwave sintered $\mathrm{NiO}$ in non aqueous electrolyte $\left(\mathrm{LiClO}_{4} 0.2 \mathrm{M}\right.$ in 3-MPN) at different scan rates presents two broad oxidation waves with reversible features (Figure 2) as observed also when $\mathrm{NiO}$ is cycled in aqueous electrolyte [20] [26] [27].

This result indicates that the processes of $\mathrm{Ni}$ oxidation in non aqueous electrolyte are of the same nature of those occurring in aqueous electrolyte [26]. When the oxidation peak at lower potential value (the one in the range $0.3-0.5 \mathrm{~V}$ vs $\mathrm{Ag} / \mathrm{AgCl}$ ) is considered, the non-hydrated nickel oxide compensates the positive charge mostly accumulated on Ni sites with the uptake of perchlorate anions as follows:

$$
\mathrm{NiO}+m \mathrm{ClO}_{4}^{-} \rightarrow \mathrm{Ni}(\mathrm{II})_{1-m} \mathrm{ONi}(\mathrm{III})_{m}\left(\mathrm{ClO}_{4}\right)_{m}+m e^{-}
$$

This evidences a behaviour typical of an intercalation material [28]-[31]. When the second oxidation peak at 


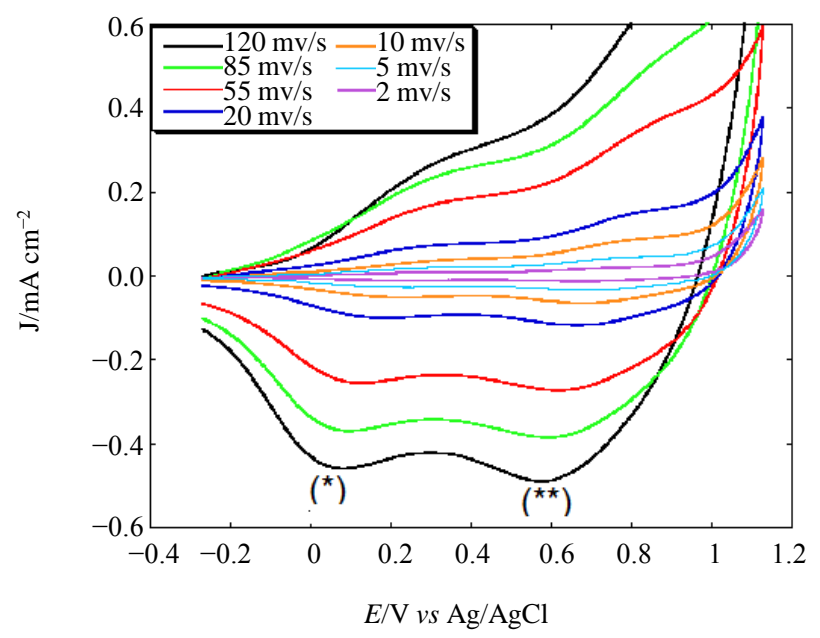

Figure 2. Cyclic voltammograms of $\mathrm{NiO}$ (thickness: $0.6 \mu \mathrm{m}$ ) at seven different scan rates ranging from 2 to $120 \mathrm{mV} \cdot \mathrm{s}^{-1}$. Electrolyte: $\mathrm{LiClO}_{4} 0.2 \mathrm{M}$ in 3-MPN.

larger potential values (i.e. the one comprised in the range 0.6 - $1.0 \mathrm{~V} v \mathrm{Ag} / \mathrm{AgCl}$, Figure 2) is considered, the mechanisms of charge compensation is

$$
\mathrm{Ni}(\mathrm{II})_{1-m} \mathrm{ONi}(\mathrm{III})_{m}\left(\mathrm{ClO}_{4}\right)_{m}+m \mathrm{ClO}_{4}^{-} \rightarrow \mathrm{Ni}(\mathrm{II})_{1-m} \mathrm{ONi}(\mathrm{IV})_{m}\left(\mathrm{ClO}_{4}\right)_{2 m}+m e^{-}
$$

In the case of Equation (2), the formation of species containing predominantly Ni(IV) is involved [32] [33]. The dependence of the current peak values with the scan rate was evaluated for the two cathodic peaks of $\mathrm{NiO}$ within the range $-0.4 \leq E \leq 1.2 \mathrm{~V}$ vs Ag/AgCl. These have been indicated with $(*)$ and $(* *)$ in Figure 2 . The linear trend of the current peaks with the scan rate of the cyclic voltammetry (Figure 3) denotes the occurrence of redox processes in $\mathrm{NiO}$, which are surface confined when $\mathrm{NiO}$ is undergoing electrochemical oxidation in non aqueous electrolyte [34].

In a successive experiment the electrochemical behavior of the same sample of $\mathrm{NiO}$ was recorded in both non aqueous and aqueous electrolytes according to the succession: TEST 1, electrolyte $0.2 \mathrm{M} \mathrm{LiClO}_{4}$ in 3-MPN; TEST 2, electrolyte $0.2 \mathrm{M} \mathrm{KCl}, 0.01 \mathrm{M} \mathrm{KH}_{2} \mathrm{PO}_{4}, 0.01 \mathrm{M} \mathrm{Na}_{2} \mathrm{HPO}_{4}$ in $\mathrm{H}_{2} \mathrm{O}$; TEST 3, electrolyte $0.2 \mathrm{M} \mathrm{LiClO}_{4}$ in 3-MPN, in order to assess the effect of surface hydration on the redox properties of NiO (Figure 4). In non aqueous environment pristine $\mathrm{NiO}$ displays the voltammogram with the lowest current density values (Cycle 1, Figure 4). Under these circumstances the mechanism of charge compensation accompanying the oxidation of $\mathrm{NiO}$ is based exclusively on the exchange of $\mathrm{ClO}_{4}^{-}$anions between the oxide surface and the electrolyte (Equations (1) and (2)). This is because $\mathrm{ClO}_{4}^{-}$is the sole negatively charged species present in the non aqueous environment here considered. The successive electrochemical cycling in water electrolyte (Cycle 2, Figure 4) brings about an increase of the current density exchanged by the $\mathrm{NiO}$ with respect to pristine $\mathrm{NiO}$ in organic electrolyte (Cycle 1, Figure 4). Such a behaviour is primarily attributed to the formation of a hydrated NiO surface upon contact of $\mathrm{NiO}$ with the aqueous electrolyte, and the occurrence of charge compensation mechanisms with the release of hydrogen cations [26]. Upon hydration of $\mathrm{NiO}$ in aqueous environment we suppose that the number of protons which are available for charge exchange on hydrated $\mathrm{NiO}$ surface, is higher than the maximum number $m$ of $\mathrm{ClO}_{4}^{-}$anions (see Equation (1)) that $\mathrm{NiO}$ can either host in its oxidized structure [28] [29] or adsorb on its oxidized surface. Such a hypothesis is supported by the further increase of the current densities with respect to the voltammetry of $\mathrm{NiO}$ in the pristine state (Cycle 1, Figure 4) when $\mathrm{NiO}$ is cycled for the second time in organic electrolyte (Cycle 3, Figure 4) immediately after the cycle in water electrolyte (Cycle 1, Figure 4). The similarity of the current profiles of Cycles 2 and 3 (Figure 4) indicates that the hydrogen cation intervenes in the mechanisms of charge compensation (Equations (1) and (2)) also in organic electrolyte when $\mathrm{NiO}$ surface is hydrated, i.e. after the realization of Cycle 2 (Figure 4) conducted in aqueous electrolyte.

Despite the increase of the amount of charge exchanged by $\mathrm{NiO}$ in aqueous environment with respect to the organic solvent 3-MPN (Figure 4), the electrochemical stability of NiO results much higher in the non aqueous environment (Figure 5) [26]. 


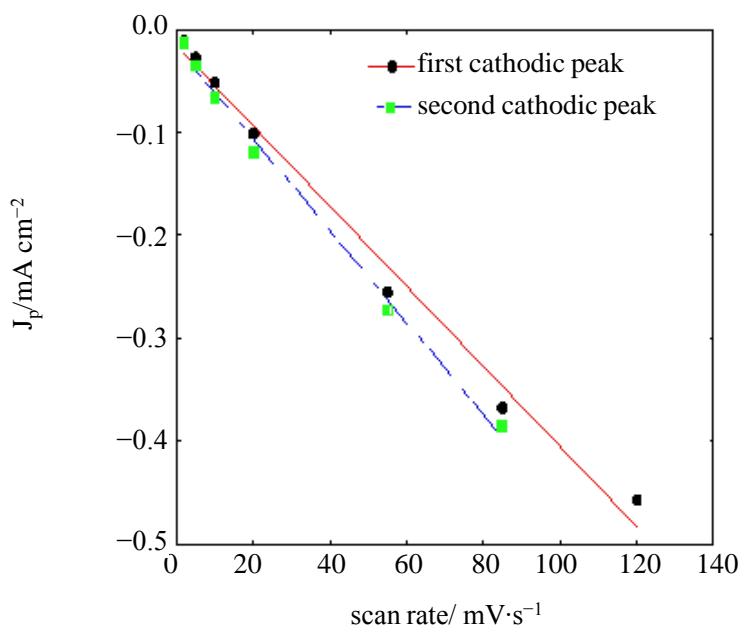

Figure 3. Linear dependence of the cathodic peak currents $\left(J_{p}\right)$ with the scan rate for the two redox processes of NiO (data extracted from Figure 2). Electrolyte: $\mathrm{LiClO}_{4} 0.2 \mathrm{M}$ in 3-MPN. First and second cathodic peak refer respectively to the peaks $\left({ }^{*}\right)$ and $\left({ }^{* *}\right)$ indicated in Figure 2.

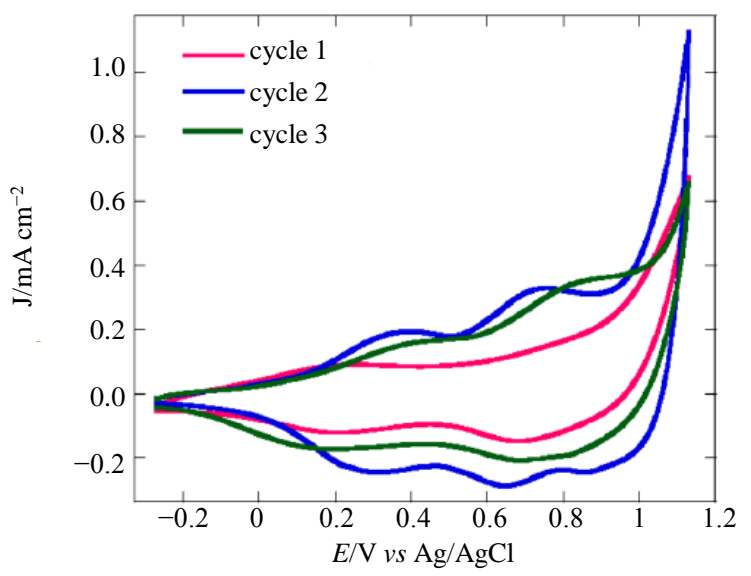

Figure 4. Cyclic voltammograms of $\mathrm{NiO}$ (thickness: $0.6 \mu \mathrm{m}$ ) at $20 \mathrm{mV} \cdot \mathrm{s}^{-1}$ in different electrolytes. Cycle 1 refers to the first cyclic voltammogram of $\mathrm{NiO}$ recorded in the non aqueous electrolyte $0.2 \mathrm{M} \mathrm{LiClO}_{4}$ in 3-MPN. Cycle 2 refers to the cyclic voltammogram of $\mathrm{NiO}$ in the aqueous electrolyte $0.2 \mathrm{M} \mathrm{KCl}, 0.01 \mathrm{M} \mathrm{KH}_{2} \mathrm{PO}_{4}, 0.01 \mathrm{M} \mathrm{Na}_{2} \mathrm{HPO}_{4}$ recorded immediately after Cycle 1 . Cycle 3 refers to the cyclic voltammogram of $\mathrm{NiO}$ recorded in $0.2 \mathrm{M} \mathrm{LiClO}_{4}$ in 3-MPN immediately after Cycle 2.

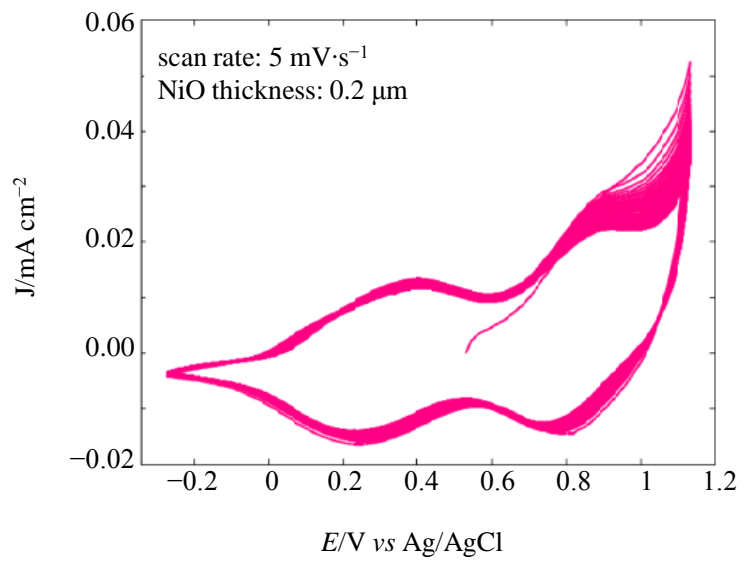

Figure 5. Continuous cycling of $\mathrm{NiO}$ (thickness: $0.2 \mu \mathrm{m}$ ) at $5 \mathrm{mV} \cdot \mathrm{s}^{-1}$ with the organic electrolyte $0.2 \mathrm{M} \mathrm{LiClO}_{4}$ in $3-\mathrm{MPN}$ 
The comparison between the second and $100^{\text {th }}$ cycle in 3-MPN electrolyte (Figure 6) shows that the extent of the surface-localized processes of NiO oxidation is not affected by continuous electrochemical cycling. This is somewhat in contrast with what we found in precedence when $\mathrm{NiO}$ was cycled in aqueous electrolyte, because continuous cycling led to the almost complete disappearance of the current associated with the oxidation of $\mathrm{NiO}$ thin film, due to the occurrence of a dissolution process introduced by extensive surface charging [31] in presence of the polar solvent $\mathrm{H}_{2} \mathrm{O}$ [26]. The improved electrochemical stability in the non aqueous electrolyte was extremely encouraging in the perspective of utilizing these $\mathrm{NiO}$ films as $p$-type photoelectrodes for water-free devices like dye-sensitised solar cells (DSCs) [11] [34] [35]. The NiO electrodes here considered possessed mesoporous features useful for DSC purposes [15] [26], since the increase of film thickness brought about the corresponding increase of the current density exchanged by electroactive NiO (Figure 7) [20].

\subsection{NiO Sensitization and DSC Performance}

The optical spectrum of plasma sintered NiO deposited onto FTO substrate is shown in Figure 8.

The intrinsic absorption of $\mathrm{NiO}$ in the near UV-visible range (Figure 8) proved to be not useful for the photoactivation of the electrochemical processes of Equations (1) and (2) based on pristine RDS NiO (Figure 2, Figure 5 and Figure 6) as verified when $\mathrm{NiO}$ electrode was irradiated with white light (Figure 9). The lack of any photoelectrochemical processes in bare $\mathrm{NiO}$ is proven by the fact that the voltammograms are practically unvaried in passing from the dark to the illuminated state for non-sensitized plasma sintered NiO (Figure 9). Any photoconduction or a photovoltaic effect would have manifested itself with the increase of the current or a shift of the potential at which $\mathrm{NiO}$ oxidation takes place under NiO illumination [34].

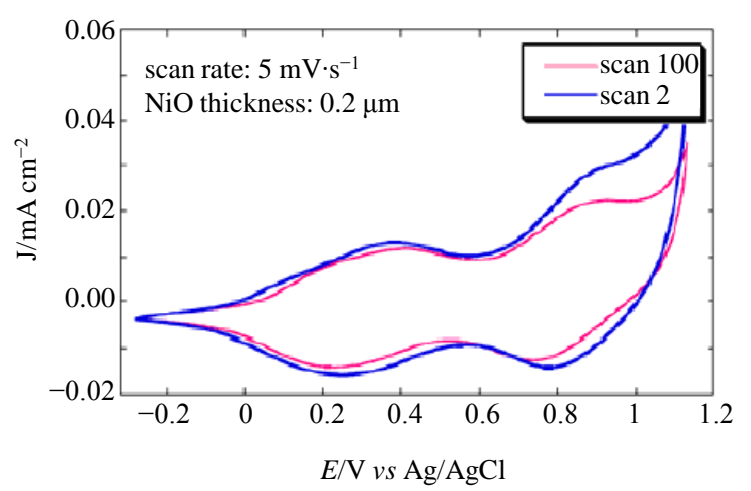

Figure 6. Comparison of the second and $100^{\text {th }}$ voltammetric cycle (data extracted from Figure 5).

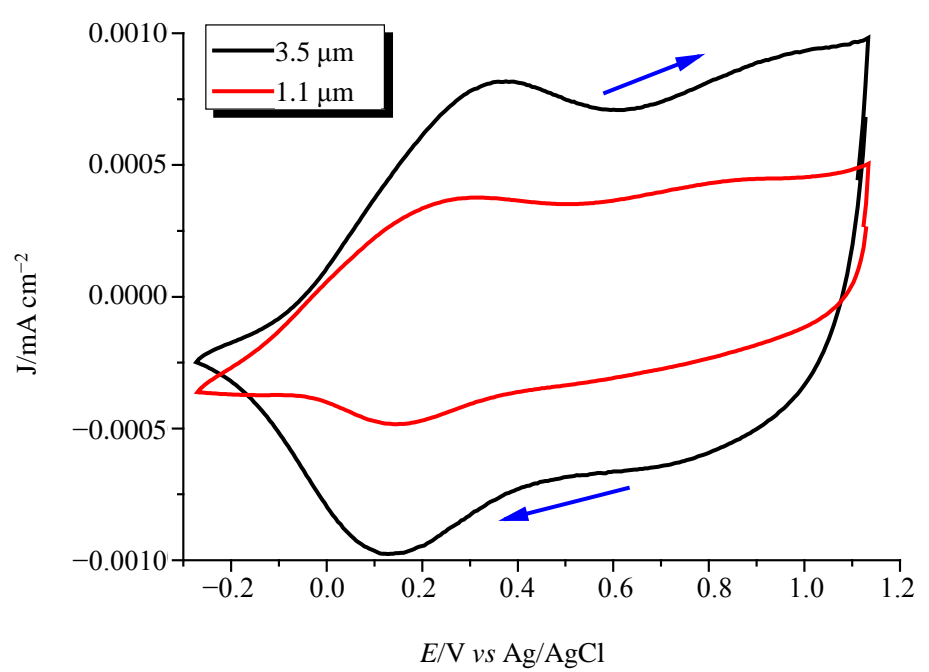

Figure 7. Cyclic voltammograms of $\mathrm{NiO}$ samples with two different thicknesses at the scan rate $20 \mathrm{mV} \cdot \mathrm{s}^{-1}$. Electrolyte: 0.2 $\mathrm{M} \mathrm{LiClO}_{4}$ in 3-MPN. Blue arrows indicate the verse of potential scan. 


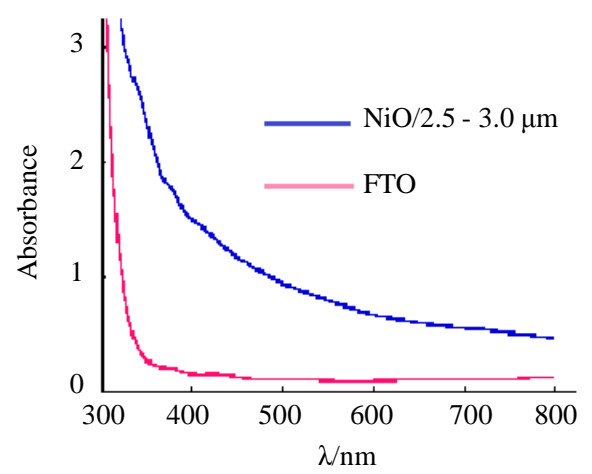

Figure 8. Optical spectra of glass/FTO substrate and glass/FTO/NiO film (blank: air). NiO film thickness: 2.5 - $3.0 \mu \mathrm{m}$.

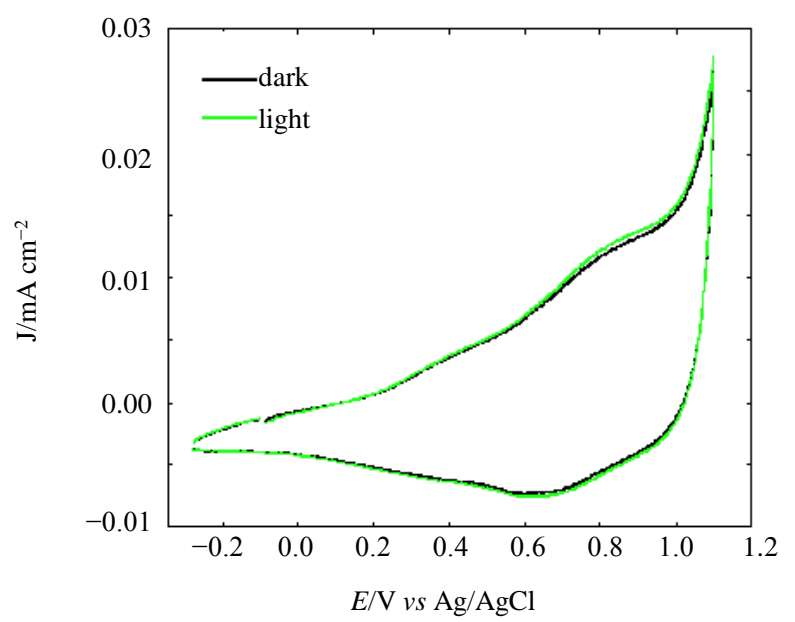

Figure 9. Cyclic voltammograms of $\mathrm{NiO}$ in $0.2 \mathrm{M} \mathrm{LiClO}_{4}$ in 3-MPN in the dark conditions and under white light irradiation. $\mathrm{NiO}$ film thickness: $0.2 \mu \mathrm{m}$; scan rate: $20 \mathrm{mV} \cdot \mathrm{s}^{-1}$. Intensity of the incident white light: $16 \mathrm{~W} \cdot \mathrm{m}^{-2}$. Average transmittance of $\mathrm{NiO}$ sample in the visible spectrum: $80 \%$.

For their employment as photoactive cathodes in $p$-DSCs, RDS NiO films were sensitized with the commercial dyes N719, BD, SQ2 and ERY B (Figure 1). With the exception of ERY B, the other three dyes N719, BD and SQ2 are typically utilized for the sensitization of $\mathrm{TiO}_{2}$ [35]. Anyhow, all of them can be used for $\mathrm{NiO}$ sensitization since possess energy levels of the frontier orbitals which match opportunely with the upper edge of the $\mathrm{VB}$ of $\mathrm{NiO}$ [36]. This allows the photoinduced injection of holes from the excited dye to the oxide VB [36]. The absorption spectra of $\mathrm{NiO}$ sensitized with the four different dyes are shown in Figure 10 (the spectra of the tincture solutions are presented in the supplementary information). The choice of a relatively thin film of $\mathrm{NiO}(l<$ $1.5 \mu \mathrm{m}$ ) for the assembly of the $p$-DSC was dictated by the strong intrinsic optical absorption of thicker NiO (Figure 8), which would not have allowed the efficient excitation of the dye-sensitizer throughout the whole film and limited the light harvesting efficiency [20] [23]. The following results will show that a relatively small thickness of $\mathrm{NiO}$ is the necessary condition to allow the meaningful comparison of the sensitizing action of the different dyes upon $\mathrm{NiO}$ and the analysis of the photoelectrochemical response in the corresponding $p$-DSCs.

Among the commercial dyes here considered (Figure 1) the organic compound SQ2 with its red-shifted and larger absorption with respect to the Ru-based dyes N719 and BD, and to organic ERY B, resulted the most effective dye in terms of sensitization of $\mathrm{NiO}$ in the NIR-visible spectrum (Figure 10). The sensitizing effect provided by SQ2 on $\mathrm{NiO}$ is also accompanied by the most efficacious action of hole photoinjection in $\mathrm{NiO}$ with respect to the other sensitizers upon cell illumination (J-V curves in Figure 11). Data from the characteristic curves of Figure 11 are listed in Table 2. The stronger photoresponse of NiO introduced by its sensitization with SQ2 is ascribed to the generally higher molar extinction coefficient of SQ2 with respect to the Ru-based dyes [37] and, eventually, to the relatively larger amounts of SQ2 dye molecules anchored per unit area of NiO with respect to the other classes of dyes as determined by experiments of absorption/desorption [38]. 


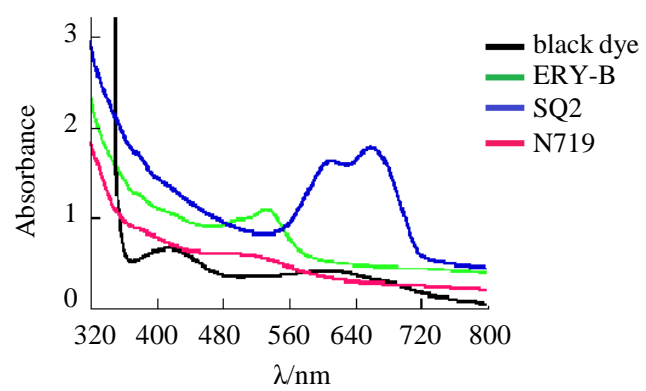

Figure 10. Optical spectra of NiO sensitized with the four different dyes of Figure 1 (blank: air). NiO film thickness: 0.8 $1.0 \mu \mathrm{m}$.

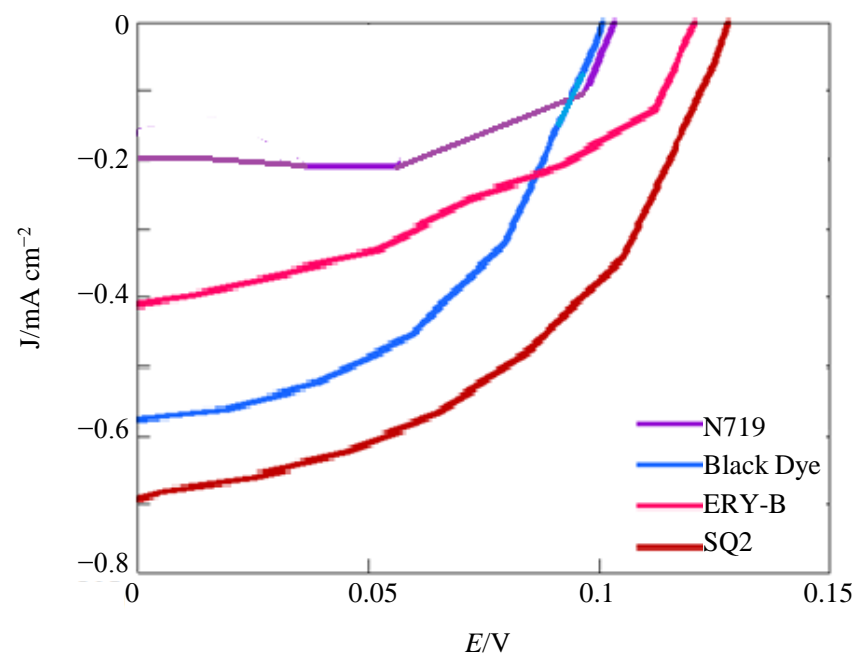

Figure 11. J-V characteristic curves of the $p$-DSCs obtained with the four differently sensitized NiO photocathodes of Figure 10. $I_{\text {in }}=8.35 \mathrm{~W} \cdot \mathrm{m}^{-2}$; $\mathrm{NiO}$ film thickness: $0.8-1.0 \mu \mathrm{m}$.

From the general comparison of the photovoltaic performances of the four different dyes it is evident that the organic sensitizers ERY B and SQ2 are those which introduce the largest photovoltages with respect to the Rubased complexes (Figure 11 and Table 1). This effect is directly associated with the strongest sensitizing effect operated by the two organic dyes with respect to the metal complexes (Figure 10). Therefore, we can conclude that the stronger the absorption (Figure 10) and the higher the number of absorbed photons per unit time by sensitized $\mathrm{NiO}$, the larger the photopotential of the corresponding $p$-DSC will be (Figure 11). As far as the sensitization of $\mathrm{NiO}$ with ERY B is concerned, we recall here that the present J-V data (Table 1) reproduce quite well our previous results obtained with the $p$-DSCs based on plasma sintered NiO photoelectrodes having similar thickness, and sensitized with the same colorant [23].

These facts can suggest a research guideline about the further optimization of the NiO photovoltaic performance in DSCs: This consists in the synthesis of new dyes having molar extinction coefficients (and probabilities of transition) in the visible-NIR range as high as possible. Another important characteristic of the new dyes has to be the capability of getting anchored on NiO surface in large amounts per surface area. In the monolayer configuration the possible intermolecular aggregation of the anchored dyes with consequent alteration of the absorption spectrum with respect to that of the free molecule, does not seem to be particularly crucial in the action of hole photoinjection in $\mathrm{NiO}$ as long as photons are efficiently absorbed. This is particularly clear in case of $\mathrm{NiO}$ sensitization with SQ2 dye for which there is spectral evidence of intermolecular aggregation when SQ2 gets anchored on NiO (Figure 10). Anyhow, such a phenomenon is not accompanied by a degradation of the photoelectrochemical response since in terms of photocurrent and fill factors the best performances of NiObased $p$-DSC are just those obtained with SQ2 and BD sensitizers. The cathodic short-circuit photocurrent densities $\left(J_{s c}\right)$ are higher than $0.5 \mathrm{~mA} \cdot \mathrm{cm}^{-2}$ for BD and SQ2 whereas ERY B displays $J_{s c}=0.4 \mathrm{~mA} \cdot \mathrm{cm}^{-2}($ Figure 11 and Table 1). This implies that the stronger absorption of light from ERY B sensitizer with respect to BD, and 
Table 1. List of the parameters derived from the J-V characteristic curves obtained with the $p$-DSCs assembled with NiO photocathodes $(l=0.8-1.0 \mu \mathrm{m})$ and the sensitizers N719, BD, ERY B and SQ2. Electrolyte composition: $0.1 \mathrm{M} \mathrm{I} 2,1.0 \mathrm{M}$ LiI in acetonitrile. $\eta$ : overall efficiency; $V_{o c}$ : open-circuit voltage; $J_{s c}$ : short circuit current density; FF: fill factor. Sintering time of the $\mathrm{NiO}$ sample is $5 \mathrm{~min}$ (see Experimental section).

\begin{tabular}{ccccc}
\hline Dye & $\eta / \%$ & $V_{\text {oc }} / \mathrm{V}$ & $-J_{\text {sc }} / \mathbf{m A} \cdot \mathbf{c m}^{-2}$ & FF \\
N719 & 0.008 & 0.103 & 0.202 & 0.319 \\
BD & 0.027 & 0.100 & 0.584 & 0.391 \\
ERY B & 0.022 & 0.125 & 0.412 & 0.358 \\
SQ2 & 0.041 & 0.132 & 0.693 & 0.376 \\
\hline
\end{tabular}

Table 2. HOMO and LUMO levels of the four dyes here considered for the sensitization of plasma sintered NiO (data taken from Ref. [36]).

\begin{tabular}{ccc}
\hline Dye & HOMO/eV & LUMO/eV \\
\hline N719 & -5.57 & -3.90 \\
BD & -5.20 & -3.80 \\
ERY B & -5.69 & -3.53 \\
SQ2 & -5.31 & -3.72 \\
\hline
\end{tabular}

the consequent more efficient hole photoinjection by ERY B vs BD for the build-up of larger photovoltages are not sufficient to produce a correspondingly higher photocurrent through sensitized NiO in $p$-DSCs (Table 1). Possible causes for the relatively good performance of BD with respect to ERY B in terms of photocurrent are the higher rate of electron transfer from $\mathrm{NiO}$ to the excited (or oxidized) state of $\mathrm{BD}$, the consequent shorter time of hole diffusion from $\mathrm{NiO}$ surface, i.e. the site of hole generation, towards the bulk of the oxide. Another factor could be also the longer lifetime of the excited state of BD with respect to ERY B, which is involved in the process of electron transfer from the dye (either in the neutral or in the reduced state) to the oxidized form of the redox couple. An analysis of the kinetic factors controlling the transport in sensitized $\mathrm{NiO}$ is beyond the scopes of the present paper. The BD anchored to $\mathrm{NiO}$ shows a better efficiency of charge transport in comparison to ERY B. At a structural level this fact could be justified with the constant presence of an electron deficient moiety represented by the positively charged ruthenium center during every step of the photocarrier generation and transfer. Ruthenium can be found either in the transient +3 state during the process of hole transfer from the oxide to $\mathrm{BD}$, or in the +2 state in the neutral and in the eventual reduced state of complex BD during the process of electron transfer from the dye to the oxidized form of the redox couple [35]. Such a kinetic driving force for the injection of holes in $\mathrm{NiO}$ is not available when organic dyes are the sensitizers. In fact, the strength of the photoaction of the organic sensitizer here considered is mostly based on the relatively higher energies of their LUMO levels with respect to Ru complexes (Table 2). This "thermodynamic" factor would favour the electron transfer from the occupied LUMO level of the excited (or reduced) state of the organic dye to the oxidized form of the redox shuttle because of the large stabilization the electron gains in passing from the LUMO level of the excited organic dye to the energy level of the redox couple.

\section{Conclusions}

Mesoporous nickel oxide (NiO) thin films have been prepared via plasma-assisted rapid discharge sintering (RDS) with microwave heating and were employed as photoactive cathodes in $p$-type dye-sensitized solar cells ( $p$-DSCs). RDS NiO films in the pristine state have a grey appearance and present a featureless absorption spectrum in the visible-NIR range. Such an absorption could not be exploited for the photoactivation of any process of charge separation upon irradiation of bare RDS NiO with white light radiation. The voltammograms of RDS $\mathrm{NiO}$ in non aqueous electrolyte present two characteristic oxidation peaks that have been ascribed to the oxidation processes $\mathrm{Ni}(\mathrm{II}) \rightarrow \mathrm{Ni}(\mathrm{III})$ and $\mathrm{Ni}(\mathrm{III}) \rightarrow \mathrm{Ni}(\mathrm{IV})$ similar to the electrochemical behaviour of $\mathrm{NiO}$ in aqueous electrolyte. The scan rate dependence of the peaks intensity in the voltammograms of $\mathrm{NiO}$ revealed a linear trend which indicated the confinement of the redox processes of $\mathrm{NiO}$ at its external surface in contact with the electrolyte. 
Upon sensitization with organometallic (N719, black dye) and organic (squaraine 2, erythrosine B) dyes RDS $\mathrm{NiO}$ becomes photoelectrochemically active towards the reduction of triodide into iodide in the corresponding $p$-DSCs. After comparing the photovoltaic performances of the four $p$-DSCs differing only for the nature of the dye we came into the conclusion that the extent of electronic conjugation in the structure of the sensitizer (or in a part of it), represents the most crucial factor for the control of the photoinjection process consisting in the concomitant transfer of a hole from $p$-type NiO to the oxidized form of the redox shuttle mediated by the excited/reduced dye. This was particularly evident when the effect of sensitization achieved with squaraine 2 was compared with the one produced by erythrosine B. An analogous consideration held when the paragon between the performances of the $p$-DSC based on black dye and the one employing N719 as sensitizers was made.

\section{Acknowledgements}

M.A., D.D. and D.P.D. wish to acknowledge the financial support from Science Foundation Ireland (Project No. 07/SRC/B1160). D.D. acknowledges the financial support from the University of Rome "LA SAPIENZA" through the program Ateneo 2012 (Protocol No. C26A124AXX). The research presented in this article was funded by the Deanship of Scientific Research (DSR), King Abdul Aziz University, Jeddah. The author M.A. acknowledges with thanks DSR for financial support.

\section{References}

[1] Adler, D. and Feinleib, J. (1970) Electrical and Optical Properties of Narrow-Band Materials. Physical Review B, 2, 3112-3134. http://dx.doi.org/10.1103/PhysRevB.2.3112

[2] Lang, J.W., Kong, L.B., Liu, M., Luo, Y.C. and Kang, L.J. (2010) Asymmetric Supercapacitors Based on Stabilized $\alpha-\mathrm{Ni}(\mathrm{OH})_{2}$ and Activated Carbon. Journal of Solid State Electrochemistry, 14, 1533-1539. http://dx.doi.org/10.1007/s10008-009-0984-1

[3] Decker, F., Passerini, S., Pileggi, R. and Scrosati, B. (1992) The Electrochromic Process in Non-Stoichiometric Nickel Oxide Thin Film Electrodes. Electrochimica Acta, 37, 1033-1038. http://dx.doi.org/10.1016/0013-4686(92)85220-F

[4] Estrada, W., Andersson, A.M., Granqvist, C.G., Gorenstein, A. and Decker, F. (1991) Infrared Reflectance Spectroscopy of Electrochromic $\mathrm{NiO}_{\mathrm{x}} \mathrm{H}_{\mathrm{y}}$ Films Made by Reactive dc Sputtering. Journal of Materials Research, 6, 1715-1719. http://dx.doi.org/10.1557/JMR.1991.1715

[5] Tong, L., Iwase, A., Nattestad, A., Bach, U., Weidelener, M., Götz, G., Mishra, A., Bäuerle, P., Amal, R., Wallace, G.G. and Mozer, A.J. (2012) Sustained Solar Hydrogen Generation Using a Dye-Sensitised NiO Photocathode/BiVO4 Tandem Photo-Electrochemical Device. Energy \& Environmental Science, 5, 9472-9475.

[6] Li, L., Duan, L., Wen, F., Li, C., Wang, M., Hagfeldt, A. and Sun, L. (2012) Visible Light Driven Hydrogen Production from a Photo-Active Cathode Based on a Molecular Catalyst and Organic Dye-Sensitized p-Type Nanostructured NiO. Chemical Communications, 48, 988-990. http://dx.doi.org/10.1039/c2cc16101j

[7] Li, L., Gibson, E.A., Qin, P., Boschloo, G., Gorlov, M., Hagfeldt, A. and Sun, L. (2010) Double-Layered NiO Photocathodes for $p$-Type DSSCs with Record IPCE. Advanced Materials, 22, 1759-1762. http://dx.doi.org/10.1002/adma.200903151

[8] Nattestad, A., Mozer, A.J., Fischer, M.K.R., Cheng, Y.B., Mishra, A., Bäuerle, P. and Bach, U. (2010) Highly Efficient Photocathodes for Dye-Sensitized Tandem Solar Cells. Nature Materials, 9, 31-35.

[9] Irwin, M.D., Buchholz, D.B., Hains, A.W., Chang, R.P.H. and Marks, T.J. (2008) p-Type Semiconducting Nickel Oxide as an Efficiency-Enhancing Anode Interfacial Layer in Polymer Bulk-Heterojunction Solar Cells. Proceedings of the National Academy of Sciences of the United States of America, 105, 2783-2787. http://dx.doi.org/10.1073/pnas.0711990105

[10] Hüfner, S. (1994) Electronic Structure of NiO and Related 3d-Transition-Metal Compounds. Advances in Physics, 43, 183-356. http://dx.doi.org/10.1080/00018739400101495

[11] O’Regan, B. and Grätzel, M. (1991) A Low-Cost, High-Efficiency Solar Cell Based on Dye-Sensitized Colloidal TiO 2 Films. Nature, 353, 737-740. http://dx.doi.org/10.1038/353737a0

[12] He, J., Lindström, H., Hagfeldt, A. and Lindquist, S.E. (2000) Dye-Sensitized Nanostructured Tandem Cell-First Demonstrated Cell with a Dye-Sensitized Photocathode. Solar Energy Materials and Solar Cells, 62, 265-273. http://dx.doi.org/10.1016/S0927-0248(99)00168-3

[13] Sumikura, S., Mori, S., Shimizu, S., Usami, H. and Suzuki, E. (2008) Syntheses of NiO Nanoporous Films Using Nonionic Triblock Co-Polymer Templates and Their Application to Photo-Cathodes of $p$-Type Dye-Sensitized Solar Cells. 
Journal of Photochemistry and Photobiology A, 199, 1-7. http://dx.doi.org/10.1016/j.jphotochem.2008.04.007

[14] Powar, S., Wu, Q., Weidelener, M., Nattestad, A., Hu, Z., Mishra, A., Bäuerle, P., Spiccia, L., Cheng, Y.B. and Bach, U. (2012) Improved Photocurrents for $p$-Type Dye-Sensitized Solar Cells Using Nano-Structured Nickel(II) Oxide Microballs. Energy \& Environmental Science, 5, 8896-8900.

[15] Awais, M., Rahman, M., Don MacElroy, J.M., Dini, D., Vos, J.G. and Dowling, D.P. (2011) Application of a Novel Microwave Plasma Treatment for the Sintering of Nickel Oxide Coatings for Use in Dye-Sensitized Solar Cells. Surface and Coatings Technology, 205, S245-S249. http://dx.doi.org/10.1016/j.surfcoat.2011.01.020

[16] Qin, P., Zhu, H., Edvinsson, T., Boschloo, G., Hagfeldt, A. and Sun, L. (2008) Design of an Organic Chromophore for p-Type Dye-Sensitized Solar Cells. Journal of the American Chemical Society, 130, 8570-8571. http://dx.doi.org/10.1021/ja8001474

[17] Odobel, F., Pellegrin, Y., Gibson, E.A., Hagfeldt, A., Smeigh, A.L. and Hammarström, L. (2012) Recent Advances and Future Directions to Optimize the Performances of $p$-Type Dye-Sensitized Solar Cells. Coordination Chemistry Reviews, 256, 2414-2423. http://dx.doi.org/10.1016/j.ccr.2012.04.017

[18] Minoura, H. and Yoshida, T. (2008) Electrodeposition of ZnO/Dye Hybrid Thin Films for Dye-Sensitized Solar Cells. Electrochemistry, 76, 109-117. http://dx.doi.org/10.5796/electrochemistry.76.109

[19] Murakami, T.N. and Grätzel, M. (2008) Counter Electrodes for DSC: Application of Functional Materials as Catalysts. Inorganica Chimica Acta, 361, 572-580. http://dx.doi.org/10.1016/j.ica.2007.09.025

[20] Gibson, E.A., Awais, M., Dini, D., Dowling, D.P., Pryce, M.T., Vos, J.G., Boschloo, G. and Hagfeldt, A. (2013) Dye Sensitised Solar Cells with Nickel Oxide Photocathodes Prepared via Scalable Microwave Sintering. Physical Chemistry Chemical Physics, 15, 2411-2420. http://dx.doi.org/10.1039/c2cp43592f

[21] Awais, M., Dini, D., Don MacElroy, J.M., Halpin, Y., Vos, J.G. and Dowling, D.P. (2013) Electrochemical Characterization of NiO Electrodes Deposited via a Scalable Powder Microblasting Technique. Journal of Electroanalytical Chemistry, 689, 185-192. http://dx.doi.org/10.1016/j.jelechem.2012.11.025

[22] Halme, J., Saarinen, J. and Lund, P. (2006) Spray Deposition and Compression of $\mathrm{TiO}_{2}$ Nanoparticle Films for DyeSensitized Solar Cells on Plastic Substrates. Solar Energy Materials and Solar Cells, 90, 887-899. http://dx.doi.org/10.1016/j.solmat.2005.05.013

[23] Awais, M., Gibson, E., Vos, J.G., Dowling, D.P., Hagfeldt, A. and Dini, D. (2014) Fabrication of Efficient NiO Photocathodes Prepared via RDS with Novel Routes of Substrate Processing for $p$-Type Dye-Sensitized Solar Cells. ChemElectroChem, 1, 384-391. http://dx.doi.org/10.1002/celc.201300178

[24] McConnell, M.L., Dowling, D.P., Pope, C., Donnelly, K., Ryder, A.G. and O’Connor, G.M. (2002) High Pressure Diamond and Diamond-Like Carbon Deposition Using a Microwave CAP Reactor. Diamond and Related Materials, 11, 1036-1040. http://dx.doi.org/10.1016/S0925-9635(01)00637-9

[25] Giustini, M., Angelone, D., Parente, M., Dini, D., Decker, F., Lanuti, A., Reale, A., Brown, T. and Di Carlo, A. (2013) Emission Spectra and Transient Photovoltage in Dye-Sensitized Solar Cells under Stress Tests. Journal of Applied Electrochemistry, 43, 209-215. http://dx.doi.org/10.1007/s10800-012-0484-3

[26] Marrani, A.G., Novelli, V., Sheehan, S., Dowling, D.P. and Dini, D. (2014) Probing the Redox States at the Surface of Electroactive Nanoporous NiO Thin Films. ACS Applied Materials \& Interfaces, 6, 143-152. http://dx.doi.org/10.1021/am403671h

[27] Boschloo, G. and Hagfeldt, A. (2001) Spectroelectrochemistry of Nanostructured NiO. Journal of Physical Chemistry B, 105, 3039-3044. http://dx.doi.org/10.1021/jp003499s

[28] Passerini, S., Scarminio, J., Scrosati, B., Zane, D. and Decker, F. (1993) Thin Metal Oxide Films on Transparent Substrates for Li-Insertion Devices. Journal of Applied Electrochemistry, 23, 1187-1195. http://dx.doi.org/10.1007/BF00625594

[29] Passerini, S. and Scrosati, B. (1994) Characterization of Nonstoichiometric Nickel Oxide Thin-Film Electrodes. Journal of the Electrochemical Society, 141, 889-895. http://dx.doi.org/10.1149/1.2054853

[30] Masetti, E., Decker, F. and Dini, D. (1995) The Electrochromic Response of Tungsten Bronzes $\mathrm{M}_{\mathrm{x}} \mathrm{WO}_{3}$ with Different Ions and Insertion Rates. Solar Energy Materials and Solar Cells, 39, 301-307. http://dx.doi.org/10.1016/0927-0248(95)00049-6

[31] Dini, D. and Decker, F. (1998) Stress in Thin Films of Metal Oxide Electrodes for Intercalation Reactions. Electrochimica Acta, 43, 2919-2923. http://dx.doi.org/10.1016/S0013-4686(98)00032-2

[32] Wherens-Dijksma, M. and Notten, P.H.L. (2006) Electrochemical Quartz Microbalance Characterization of Ni(OH) $2^{-}$ Based Thin Film Electrodes. Electrochimica Acta, 51, 3609-3621. http://dx.doi.org/10.1016/j.electacta.2005.10.022

[33] Beverskog, B. and Puigdomenech, I. (1997) Revised Pourbaix Diagrams for Nickel at $25^{\circ} \mathrm{C}-300^{\circ} \mathrm{C}$. Corrosion Science, 39, 969-980. http://dx.doi.org/10.1016/S0010-938X(97)00002-4 


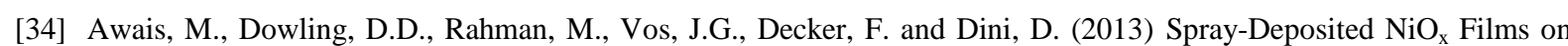
ITO Substrates as Photoactive Electrodes for $p$-Type Dye-Sensitized Solar Cells. Journal of Applied Electrochemistry, 43, 191-197. http://dx.doi.org/10.1007/s10800-012-0506-1

[35] Hagfeldt, A., Boschloo, G., Sun, L., Kloo, L. and Pettersson, H. (2010) Dye-Sensitized Solar Cells. Chemical Reviews, 110, 6595-6663. http://dx.doi.org/10.1021/cr900356p

[36] Nattestad, A., Ferguson, M., Kerr, R., Cheng, Y.B. and Bach, U. (2008) Dye-Sensitized Nickel(II)oxide Photocathodes for Tandem Solar Cell Applications. Nanotechnology, 19, Article ID: 295304. http://dx.doi.org/10.1088/0957-4484/19/29/295304

[37] Chang, C.H., Chen, Y.C., Hsu, C.Y., Chou, H.H. and Lin, J.T. (2012) Squaraine-Arylamine Sensitizers for Highly Efficient p-Type Dye-Sensitized Solar Cells. Organic Letters, 14, 4726-4729. http://dx.doi.org/10.1021/ol301860w

[38] Venditti, I., Barbero, N., Russo, M.V., Di Carlo, A., Decker, F., Fratoddi, I., Barolo, C. and Dini, D. (2014) Electrodeposited $\mathrm{ZnO}$ with Squaraine Sentisizers as Photoactive Anode of DSCs. Materials Research Express, 1, Article ID: 015040. http://dx.doi.org/10.1088/2053-1591/1/1/015040 
Scientific Research Publishing (SCIRP) is one of the largest Open Access journal publishers. It is currently publishing more than 200 open access, online, peer-reviewed journals covering a wide range of academic disciplines. SCIRP serves the worldwide academic communities and contributes to the progress and application of science with its publication.

Other selected journals from SCIRP are listed as below. Submit your manuscript to us via either submit@scirp.org or Online Submission Portal.
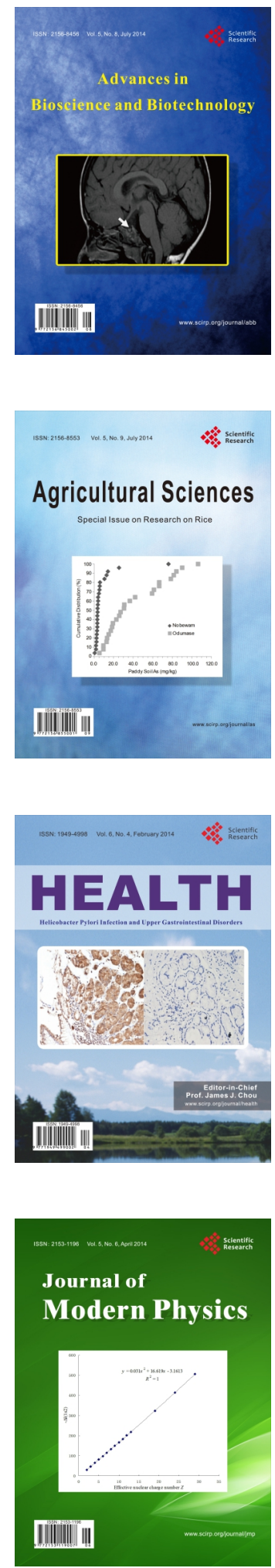
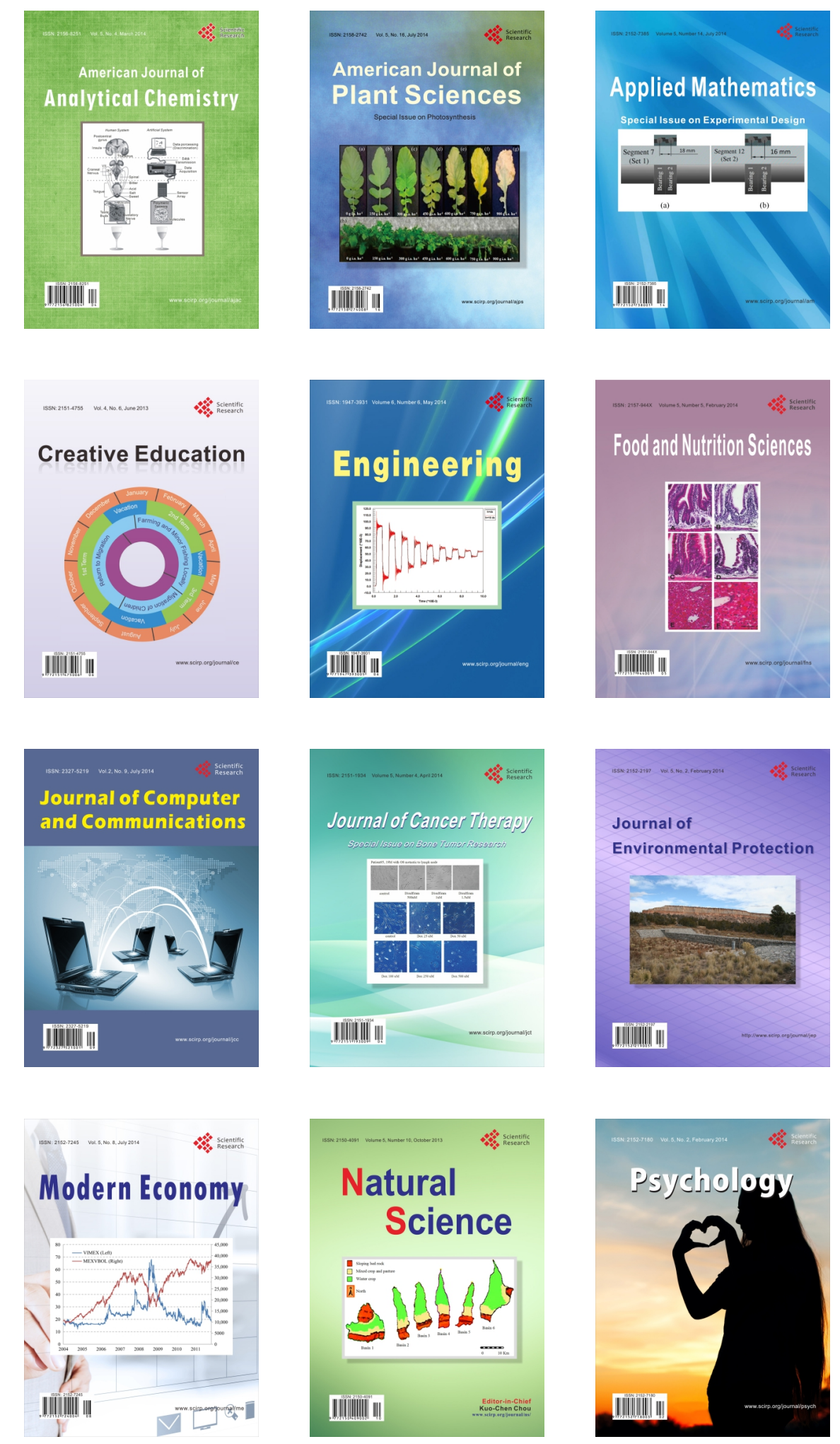